\title{
Comparison between the measured and predicted parameters of HF radio signals propagating along the midlatitude trough and within the polar cap
}

\author{
A. J. Stocker, ${ }^{1}$ E. M. Warrington, ${ }^{1}$ and D. R. Siddle ${ }^{1}$ \\ Received 20 August 2006; revised 14 March 2007; accepted 28 March 2007; published 19 June 2007. \\ [1] Prediction of the propagation characteristics of HF signals is an important aspect in \\ the planning and operation of radio systems operating within that frequency band. \\ Various computer codes have been developed by a number of organizations for this \\ purpose. These prediction techniques assume that propagation is along the great circle \\ path and ignore the effects of various large-scale ionospheric structures that can be present \\ in the northerly ionosphere and result in propagation well displaced from the great \\ circle path. This paper reports on a statistical analysis of observations of the direction of \\ arrival and signal strength, and their comparison with VOACAP predictions for four paths, \\ two roughly tangential to the midlatitude trough, one trans-auroral, and one entirely \\ located within the polar cap.
}

Citation: Stocker, A. J., E. M. Warrington, and D. R. Siddle (2007), Comparison between the measured and predicted parameters of HF radio signals propagating along the midlatitude trough and within the polar cap, Radio Sci., 42, RS3019, doi:10.1029/2006RS003557.

\section{Introduction}

[2] Prediction of the propagation characteristics of HF signals is an important aspect in the planning and operation of radio systems operating within that frequency band. Various computer codes have been developed by a number of organizations for this purpose, the Voice of America Coverage Analysis Program (VOACAP) [Sweeney et al., 1993; Lane, 2001] and the International Telecommunication Union (ITU) REC533 program [ITU-R, 2001] being two common examples of such codes. Given the system parameters (e.g., transmitter and receiver locations, frequency, power, antenna types and local noise level at the receiver), a wide variety of parameters including the most likely ionospheric modes of propagation, the associated elevation angles, and the signal to noise ratio may be predicted. These prediction techniques assume that propagation is along the great circle path and ignore the effects of various large-scale ionospheric structures. For example, the presence of the midlatitude trough (a region of depleted electron density) and polar cap phenomena such as convecting patches and sun-aligned arcs (features incorporating enhanced electron densities), can result in propagation well dis-

\footnotetext{
${ }^{1}$ Department of Engineering, University of Leicester, Leicester, U. K.
}

Copyright 2007 by the American Geophysical Union. 0048-6604/07/2006RS003557\$11.00 placed from the great circle path (GCP) when signals traverse these regions [e.g., Bates et al., 1966; Whale, 1969; Rogers et al., 1997; Warrington et al., 1997; Stocker et al., 2003; Hunsucker and Hargreaves, 2003; Siddle et al., 2004a]. The relative simplicity of operation and low computational requirements of these prediction programs compared to other techniques (e.g., ray-tracing) makes them popular with a wide range of users including broadcasters, the military, and radio amateurs. Other approaches such as near real-time forecasting [e.g., Stanislawska et al., 2006] require access to ionospheric (and other) measurements and are currently limited to short-term predictions albeit with more accuracy than the models, such as VOACAP, that are based on monthly databases.

[3] Recently there has been some interest in testing the performance of VOACAP in predicting the propagation of HF signals over a range of paths and conditions. For example, Goodman and Ballard [2004] compared measurements of maximum observable frequency in the polar cap with VOACAP predictions and found the upperdecile of their observations was considerably higher than that predicted by VOACAP; a result they attributed to the presence of polar cap patches. At midlatitudes, McNamara et al. [2006] compared signal strength measurements with predictions and found root mean square (RMS) errors ranging in values up to $15 \mathrm{~dB}$, depending on time of time, path, and operating frequency. In this 
paper we will examine the accuracy of VOACAP for paths within the polar cap, trans-oval, and oriented along the subauroral trough, and relate any inaccuracies to the prevailing propagation mechanisms; in particular where there are significant deviations from the GCP (since azimuth of arrival is not accounted for in VOACAP). Observations from a number of long-term experiments conducted in these regions over periods ranging from 15 months to three years are compared to predictions. Measurements from two paths oriented along the trough were obtained for conditions near sunspot minimum (Halifax-Leitrim, Canada) [Rogers et al., 1997] and near sunspot maximum (Uppsala-Leicester) [Siddle et al., 2004a], while observations for two further paths, one in the polar cap (Iqaluit-Alert) and one crossing the auroral oval (Halifax-Alert), were taken over a period of several years just prior to sunspot minimum [Warrington et al., 1997].

\section{Midlatitude Trough}

[4] The midlatitude ionospheric trough is a relatively narrow (a few degrees of latitude) region of reduced electron density. It occurs equatorwards of the auroral oval, quite often during the winter months, less often during the equinoxes, and rarely during summer. The trough is a nighttime phenomenon, with the onset time largely dependent on geomagnetic activity, and the closing time corresponding to sunrise at ionospheric heights. Various models have been developed to predict the occurrence, intensity, and position of the trough [e.g., Halcrow and Nisbet, 1977; Feichter and Leitinger, 2002].

[5] The effect of the trough on the azimuthal angle of arrival (bearing) and signal strength of HF signals for conditions near solar minimum has been measured on paths of $910 \mathrm{~km}$ and $4490 \mathrm{~km}$ by Rogers et al. [1997]. For the shorter path, very large bearing deviations of up to $\pm 100^{\circ}$ starting at times before local midnight were a common feature at a frequency of $5.1 \mathrm{MHz}$. The deviations were positive, negative or sometimes in both directions. During disturbed times, the large bearing deviations tended to start a few hours earlier with the time of occurrence strongly related to $A_{p}$. At higher frequencies (10.9 and $15.9 \mathrm{MHz})$, the large deviations from the GCP were much less common since the signal was usually lost after sunset due to the low maximum usable frequency (MUF) and not reacquired until sunrise. A ray tracing study [Siddle et al., 2004b] found that the change in azimuth was consistent with the refraction of the signal by the density gradients present in the walls of the trough. For the long path, after the onset of a geomagnetic storm the propagation was often to the north of the GCP either as a result of reflection from density gradients in the north wall or forward scatter from irregularities [Rogers et al., 1997]. Similar behavior has also been observed on much longer propagation paths during substorm expansion [Blagoveshchensky and Borisova, 2000]. Ray tracing simulations found that at other times, the signals on the long path that arrived at the receiver deviated equatorwards of the great circle were likely to have undergone sea scatter from regions well to the south of the trough [Stocker et al., 2003].

[6] Near solar maximum in 2000-2002, observations were made on a $1400 \mathrm{~km}$ path between Uppsala (Sweden) and Leicester (UK). Deviations of up to $50^{\circ}$ from the great circle were found, but, in contrast to the earlier experiment, the signals nearly always came from the north [Siddle et al., 2004a]. A ray tracing simulation [Siddle et al., 2004b] found that whilst the gradients in the wall of the trough were able to support off-great circle reflections at sunspot minimum when the electron density depletion is greater, this was not the case at sunspot maximum. The simulation, together with estimates of the signal reflection position derived from azimuth, elevation and time-of-flight measurements, determined that the signals deviated to the north were likely to have scattered from field-aligned irregularities located either in the wall of the trough or in the auroral oval.

\section{Polar Cap Ionosphere}

[7] Observations over recent years have established that large-scale electron density structures are a common feature of the polar cap $F$ region ionosphere. During periods when the Interplanetary Magnetic Field (IMF) is directed southwards $(\mathrm{Bz}<0)$ and geomagnetic activity is generally high, patches of plasma $100-1000 \mathrm{~km}$ across with electron density enhancements of up to a factor of 10 above the background densities have been observed in the high latitude $F$ region ionosphere. These drift antisunwards across the central polar cap at velocities of a few kilometres per second in the high latitude convection current flows [Buchau et al., 1983; Weber et al., 1984]. When geomagnetic activity is low and the IMF is directed northward (approximately $50 \%$ of the time), Sun-Earth aligned arcs of plasma with electron density enhancements of a factor of 2-3 above the background can occur. These plasma striations are elongated for thousands of kilometres in the trans-polar noon-midnight direction but are much narrower (around $100 \mathrm{~km}$ ) in the dawn-dusk direction. These features, which can persist for periods often in excess of one hour in the background $F$ region ionosphere [Carlson et al., 1984], have been found to be approximately twice as prevalent in the morning sector as in the evening sector [Gussenhoven, 1982]. They drift across the polar cap at velocities of a few hundred metres per second, generally in a duskward direction [Buchau et al., 1983].

[8] The electron density gradients associated with these large-scale electron density structures form tilted 


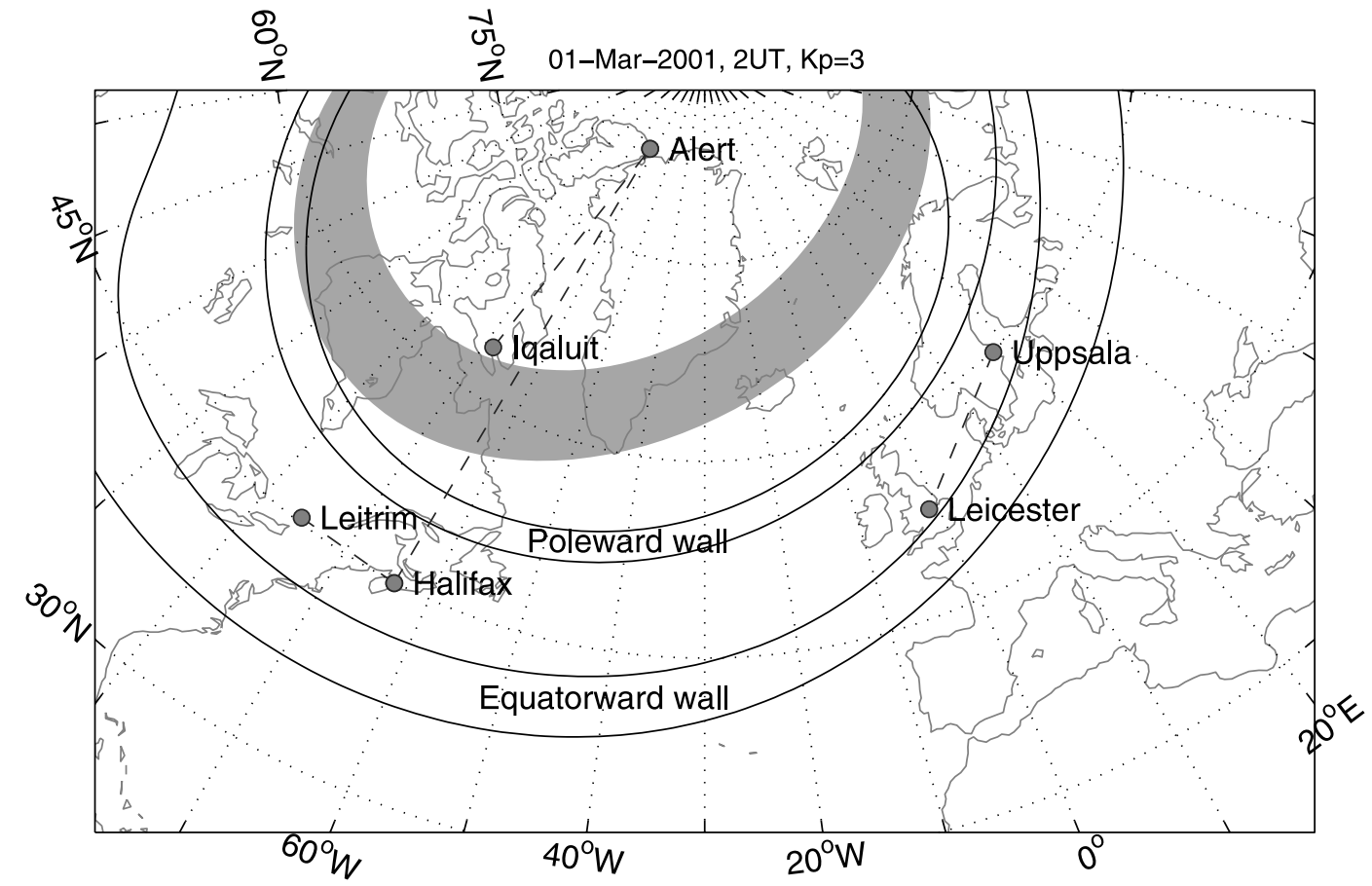

Figure 1. Map of the various experimental sites described in the text. The statistical positions of the trough [Halcrow and Nisbet, 1977] at 0200 UT on 1 March 2001 for Kp $=3$ and auroral oval (shaded) [Holzworth and Meng, 1975] are also given.

reflection surfaces for HF radio waves allowing off-great circle propagation paths to be established between the transmitter and the receiver. In order to investigate this type of propagation, a series of experiments [Warrington et al., 1997] were undertaken in which the bearings and signal characteristics of a number of HF transmissions were measured by means of a wide aperture goniometric direction finding (DF) system located at Alert in northern Canada (see Figure 1). Large quasi-periodic bearing variations of up to $\pm 100^{\circ}$ from the great circle direction were observed. Simulations using ray tracing and a realistic model of the polar cap ionosphere [Zaalov et al., 2003, 2005] have indicated that the behavior of the observed off-Great Circle (GC) signals is broadly consistent with reflection from patches and arcs.

\section{Experimental Arrangement}

\subsection{Trough Paths}

[9] Measurements on paths aligned along the trough were made over two paths. Observations on the first path were obtained during a period of 15 months (October 2000 to January 2002) near sunspot maximum. Barker13 coded binary phase shift keyed (BPSK) signals were radiated on six frequencies in the lower HF band (4-
$18 \mathrm{MHz}$ ) from a site located to the north of Uppsala, Sweden (see Figure 1). The signals were received on a 6-channel superresolution direction finding system deployed about $15 \mathrm{~km}$ south of Leicester, U.K (path length $1440 \mathrm{~km}$; great circle direction at the receiver $46^{\circ}$; midpoint local time LT $\approx \mathrm{UT}+0.5$ ). This system was able to measure the relative signal strength, absolute time-of-flight (TOF), and direction of arrival (both azimuth and elevation) of the received signal. Results obtained from both this experiment and ray-tracing simulations have been reported elsewhere [Warrington and Stocker, 2003; Siddle et al., 2004a, 2004b].

[10] Rogers et al. [1997] have previously described the experimental systems used on the second trough-aligned path from Halifax to Leitrim, Canada $(910 \mathrm{~km}$; bearing $89^{\circ} ; \mathrm{LT} \approx \mathrm{UT}-4.7$ ). The bearing and signal strength (in terms of the voltage at the receiver input) were measured between December 1993 and November 1994 (near sunspot minimum) at three frequencies $(5.1,10.9$, and 15.9 MHz). A goniometric direction finding system was employed for the directional measurements; the amplitude measurements were obtained with a separate receiver connected to an elevated feed vertical monopole antenna. The signal radiated from Halifax, which was not under the authors' control, was modulated using frequency shift keying (FSK), the presence of which allowed a 
crude form of signal recognition to be applied (identification of the signal peak and sidebands), although this was not as effective as for the Uppsala-Leicester case where the Barker coding meant that the sounding signal could be readily identified. For the Halifax-Leitrim (and for the other Canadian paths given in Figure 1 and described in the next subsection), the observations were manually inspected and data that could not be identified with confidence as originating from the transmitters of interest were removed from the analysis. Although this process is not ideal, where any doubt exists as to the provenance of the measurement we have exercised caution so that extraneous signals are unlikely to contaminate the statistics, although conversely, some valid data may have been discarded.

\subsection{Polar Cap and Trans-Auroral Oval Path}

[11] The experimental arrangement (see Figure 1) for the paths in the polar cap (Iqaluit-Alert; $2090 \mathrm{~km} ; 189^{\circ}$; $\mathrm{LT} \approx \mathrm{UT}-4.5$ ) and trans-auroral oval (Halifax-Alert; $4200 \mathrm{~km} ; 182^{\circ}$; LT $\left.\approx \mathrm{UT}-4.25\right)$ was similar to that briefly described above for Halifax-Leitrim with several exceptions. Firstly, the frequencies transmitted from Iqaluit were 5.8, 9.3, and $20.3 \mathrm{MHz}$, secondly, the modulation was ASK (a Morse call sign provided a rudimentary form of signal recognition), and thirdly the signal strength measurements at Alert were unreliable. Therefore, the probability that the signal was successfully received (in effect the number of times the signal exceeded the threshold signal to noise ratio (SNR) required for a successful measurement to be made by the DF), expressed as a percentage of the total number of observations made, will be presented instead of signal strength. Whilst the resulting probability of occurrence is not an ideal metric, provided the signal strength is sometimes above and sometimes below the threshold SNR required for successful reception then it does afford an indication of the signal strength.

\section{Observations and Predictions}

[12] The databases used by VOACAP (and REC533) provide predictions by hour and month, and therefore, in order to facilitate a comparison between the experimental measurements and the predicted parameters, the statistical behavior of the observations are also presented in this way. The VOACAP (version 05.0119) predictions have been produced using method 25 (the "all modes table" in which the results from each of the potential propagation modes were output individually) in order to obtain information on each of the potential propagation modes. All VOACAP analysis has been done using the CCIR (International Radio Consultative Committee) ionospheric coefficients, the international smoothed sunspot number (SSN) appropriate to the month and year, and a minimum take off angle of $3^{\circ}$. Weak modes with a carrier to noise density ratio (CNR - in effect the SNR in a $1 \mathrm{~Hz}$ bandwidth) below a given threshold (this was receive site and frequency dependent, although the choice of threshold does not significantly affect the results) and those for which the predicted probability of occurrence was zero (i.e., the parameter MUFday $=0 \%$ ) were excluded from the analysis. The sporadic $E$ model that is available in VOACAP was not utilized since there is some doubt as to whether it can provide an accurate prediction of signal strength [Lane, 2001], hence the sporadic $E$ layers observed experimentally are not reproduced in the prediction results. An examination of the sporadic $E$ layers observed on the Uppsala-Leicester path will be the subject of a future paper.

[13] Although the Uppsala-Leicester observations were collected several years after the Halifax-Leitrim data, they will be discussed first since the propagation mechanisms are more straightforward than for the earlier experiments.

\subsection{Trough Path Near Sunspot Maximum (Uppsala-Leicester)}

[14] The monthly-by-hour occurrence statistics for measured and predicted TOF as a function of frequency (for winter) and season (for $11.1 \mathrm{MHz}$ ) are given in Figures 2 and 3, respectively. Measurements were made on each frequency every three minutes with the result that up to 600 observations were included in each monthhour. In Figure 2, the propagation observed during the day is largely as predicted. At the lowest frequency (4.6 MHz) the signal is not detected because of $D$ region absorption, while at higher frequencies $1 \mathrm{~F}, 2 \mathrm{~F}$, and, up to 11.1 MHz, 3F modes are observed close to the times given by VOACAP. It should be noted that the weak daytime $3 \mathrm{~F}$ mode observed at $14.4 \mathrm{MHz}$ and the $2 \mathrm{~F}$ mode at $18.4 \mathrm{MHz}$ are not predicted because there is insufficient electron density in the model to support propagation. However, the $4 \mathrm{~F}$ modes observed at 10 and $11 \mathrm{MHz}$

Figure 2. Absolute time of flight versus time of day for Uppsala-Leicester in December $2001(\mathrm{SSN}=115)$ at frequencies of (top to bottom) 4.6, 7.0, 10.4, 11.1, 14.4, and 18.4 MHz. The left-hand panels are derived from experimental data with the color scale indicating the number of observations (i.e., a measure of the probability of occurrence). The right-hand panels are derived from VOACAP predictions, the color scale giving the percentage of days for which the mode MUF is above the operating frequency. The monthly mean times when the path midpoint at $200 \mathrm{~km}$ altitude was sunlit are indicated by the solid bar at the top of each panel. 

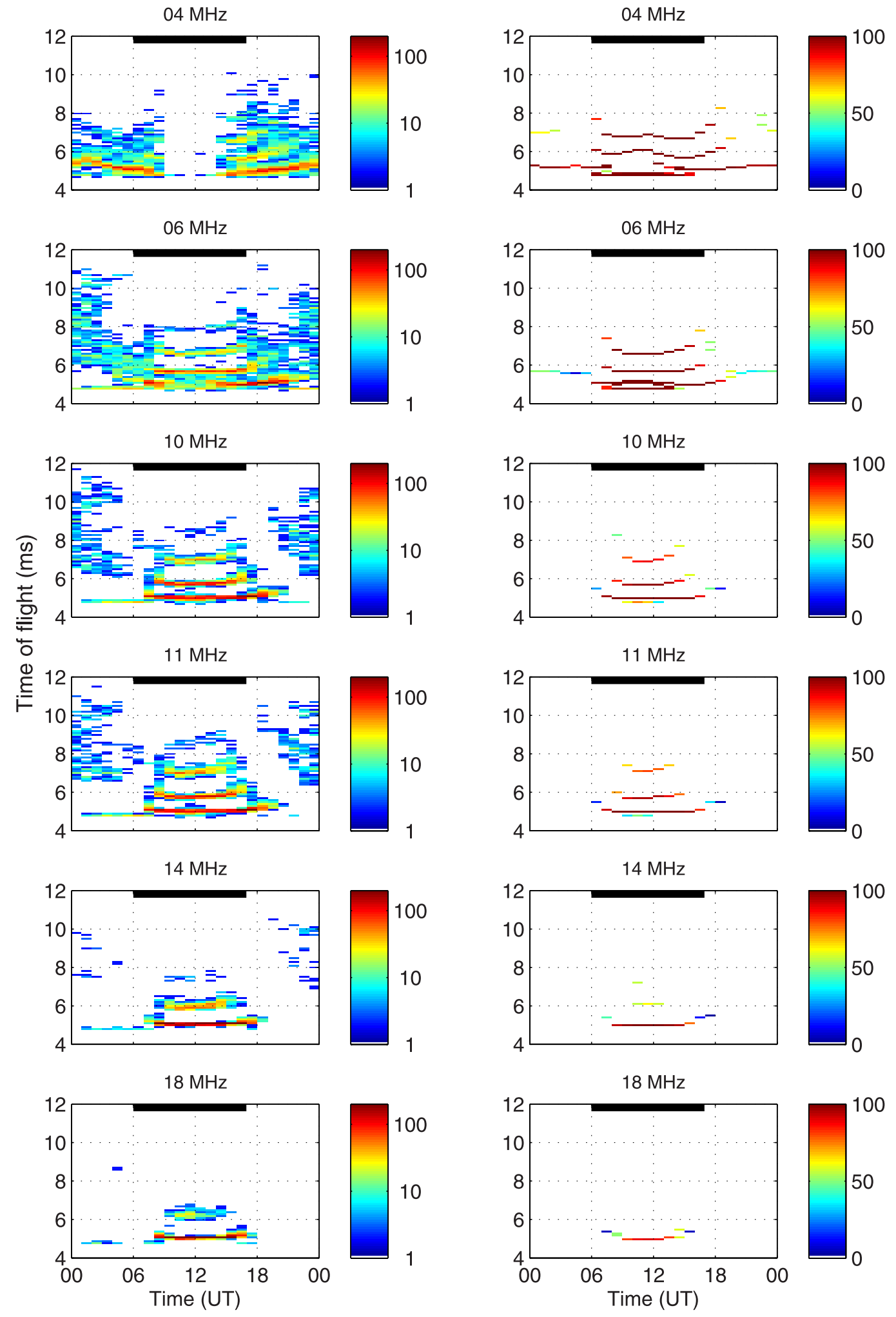

Figure 2 

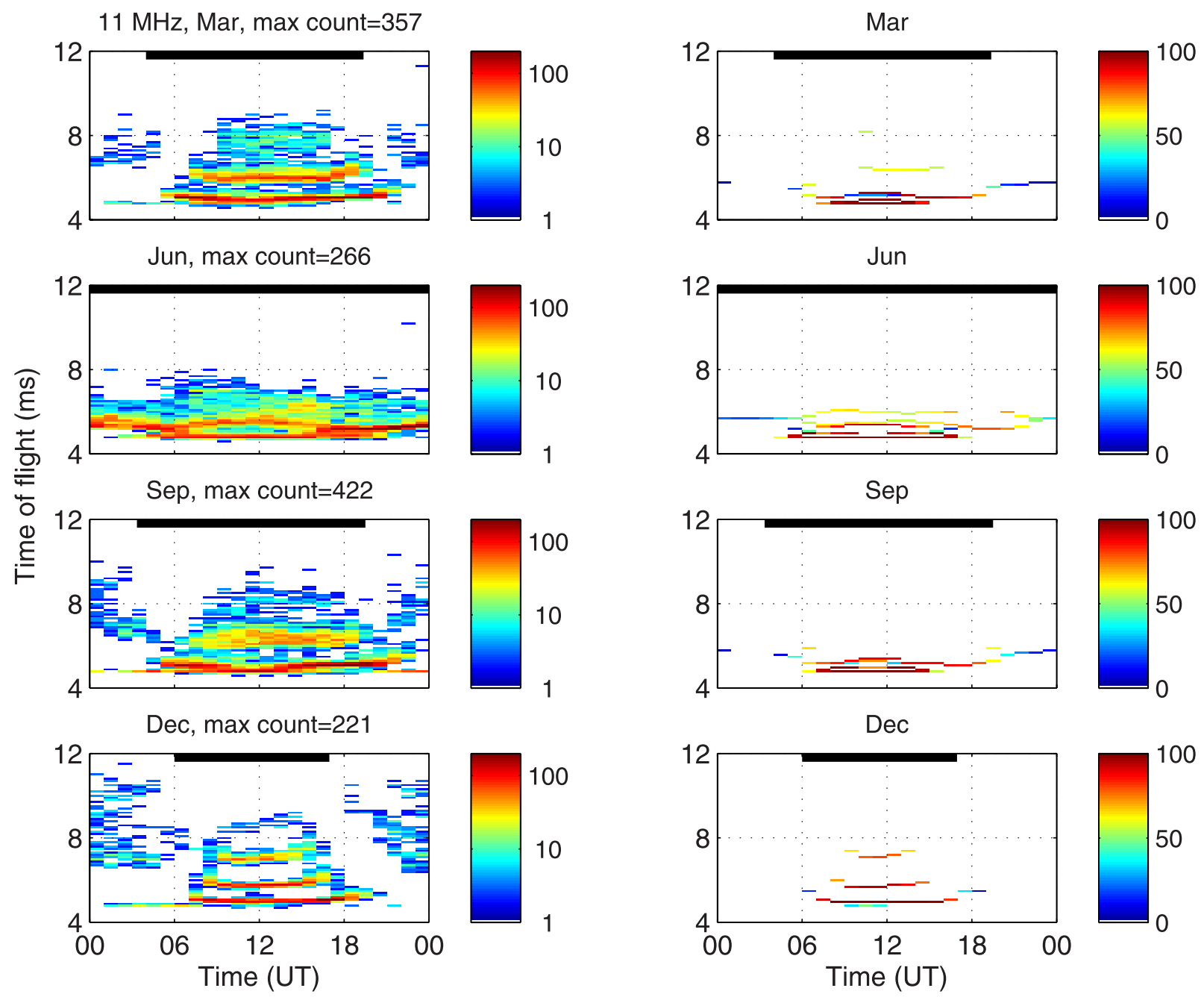

Figure 3. Time of flight versus time of day for the $11 \mathrm{MHz}$ signal transmitted from Uppsala and received in Leicester in (top to bottom) March, June, September, and December (SSN = 105, 110, 114, and 115, respectively). The left-hand panels are experimental data, and the right-hand panels are derived from VOACAP. The color scales and the solid bar at the top of each panel are as described in Figure 2.

are not predicted because VOACAP is limited to calculating the propagation for the lowest three modes that reflect from a given ionospheric layer (i.e., in this case, 1F2, 2F2, and 3F2). At night, VOACAP does not perform well since the propagation at long TOF (7 to $11 \mathrm{~ms}$ ) that is present in the observations from about $2000 \mathrm{UT}$ through to $0600 \mathrm{UT}$, particularly for $7-11 \mathrm{MHz}$, is not reproduced. These propagation modes have been found to be consistent with the scattering of the signal from field-aligned irregularities located either in the north wall of the trough or in the auroral oval [Siddle et al., $2004 b]$. As noted earlier, the sporadic $E$ observed at a TOF of just less than $5 \mathrm{~ms}$ will not be present in the predictions since this part of the model has been disabled.

[15] The seasonal variation of the observed and predicted TOF for a frequency of $11.1 \mathrm{MHz}$ is presented in Figure 3. During the day at all times, and at night in summer the observations are generally in quite close agreement with the predictions. However, the resolution of the measurements and transmitted pulse width $(0.05$ and $0.6 \mathrm{~ms}$, respectively) precludes resolving the $1 \mathrm{E}$ and $1 \mathrm{~F} 1$ modes in the summer daytime, and the delay for the summer night-time mode is slightly longer than that predicted. In the nonsummer months when the propaga- 

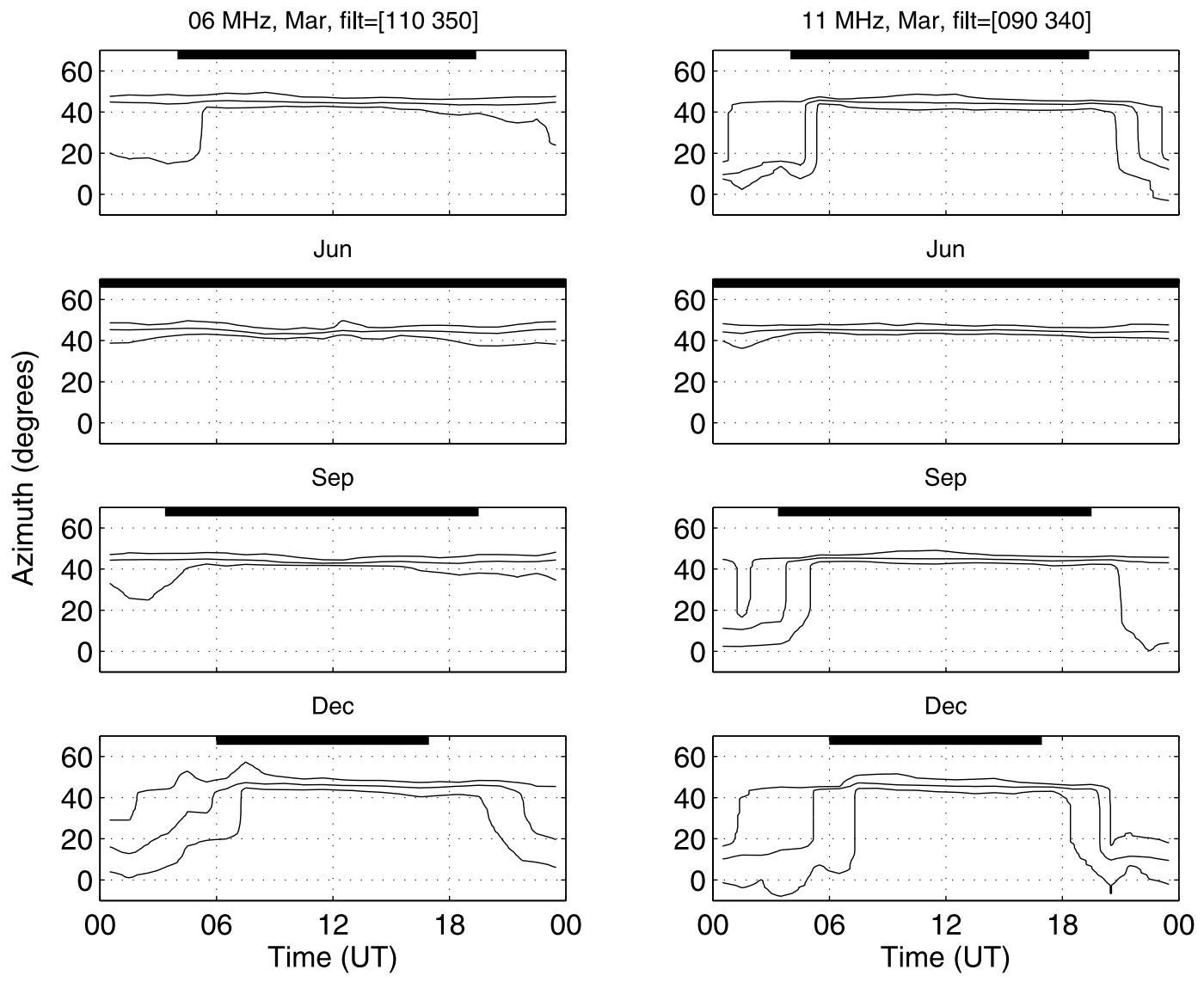

Figure 4. Plots of the observed median (middle line) and upper (top line) and lower decile (bottom line) values of azimuth as a function of time of day for Uppsala-Leicester in (top to bottom) March, June, September, and December. The left-hand panels are for $7.0 \mathrm{MHz}$, and the right-hand panels are for $11.1 \mathrm{MHz}$. The solid bar at the top of each panel is described in Figure 2.

tion modes at long TOF are commonly observed at night, these are not predicted by VOACAP. Furthermore, the $F$ region mode predicted just before midnight in March, and to an extent in September, is not present in the observations. It is likely that the reduction in the on-GCP MUF due to the presence of the trough is not reproduced in the VOACAP model and consequently leads to prediction of modes that are not actually present.

[16] The bearing measurements are presented in two different, but related forms. In the first, the hourly lowerdecile, median and upper decile azimuthal $(A)$ values (i.e., the values not exceeded by 10,50 , and $90 \%$ of the observations, respectively) observed for $7.0 \mathrm{MHz}$ and 11.1 MHz are presented in Figure 4. In the second, the median and upper-decile values of the absolute deviations in measured azimuth from the GC $(\triangle A=\mid A-$ $A_{G C P} \mid$ ) for a four-hour interval around the path-midpoint local midnight are given in Table 1. For all seasons the direction of arrival measured during the day is close to
Table 1. Median (50) and Upper-Decile (90) Azimuth Deviations From GC, $\triangle A$ Observed for Uppsala-Leicester Around Local Midnight (2300-0300 UT) in 2001 ${ }^{\mathrm{a}}$

\begin{tabular}{|c|c|c|c|c|c|c|}
\hline & \multicolumn{2}{|c|}{ 4.6 MHz } & \multicolumn{2}{|c|}{$7.0 \mathrm{MHz}$} & \multicolumn{2}{|c|}{$10.4 \mathrm{MHz}$} \\
\hline & 50 & 90 & 50 & 90 & 50 & 90 \\
\hline Jan & 2 & 11 & - & - & - & - \\
\hline Feb & 3 & 7 & 14 & 35 & 28 & 40 \\
\hline Mar & 2 & 6 & 3 & 26 & 30 & 42 \\
\hline Apr & 2 & 11 & 3 & 24 & 7 & 40 \\
\hline May & 2 & 6 & 3 & 9 & 2 & 17 \\
\hline Jun & 3 & 7 & 2 & 8 & 2 & 5 \\
\hline Jul & 2 & 7 & 2 & 6 & 2 & 8 \\
\hline Aug & 3 & 10 & 2 & 5 & 1 & 22 \\
\hline Sep & 3 & 13 & 2 & 16 & 29 & 44 \\
\hline Oct & 3 & 10 & 2 & 26 & 30 & 52 \\
\hline Nov & 3 & 11 & 5 & 36 & 32 & 49 \\
\hline Dec & 3 & 19 & 31 & 43 & 36 & 50 \\
\hline
\end{tabular}

aNote: The results for months with fewer than 100 measurements have been omitted. 

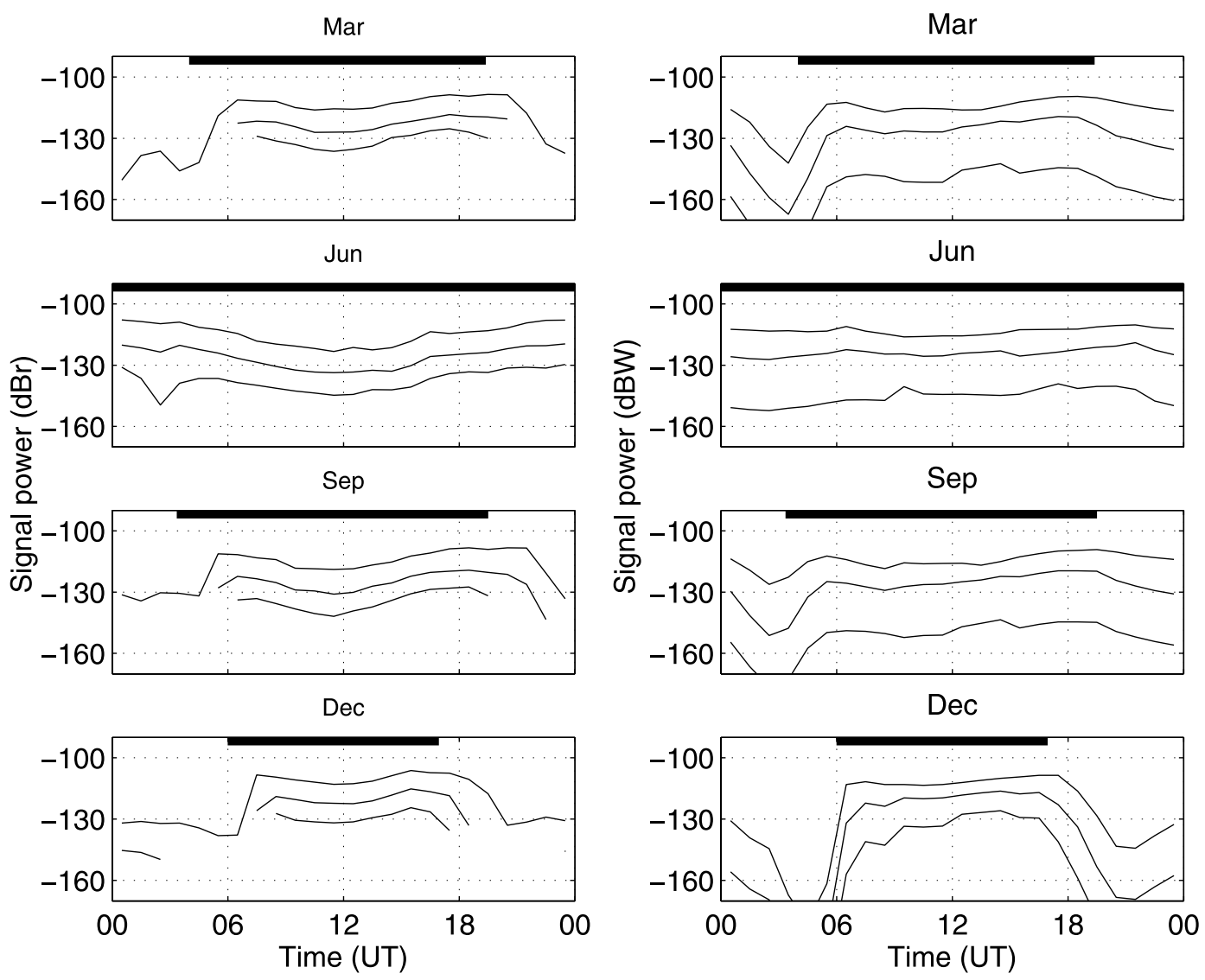

Figure 5. Signal strength versus time of day for an $11.1 \mathrm{MHz}$ signal transmitted from Uppsala to Leicester in (top to bottom) March, June, September, and December 2001 (SSN = 105, 110, 114, and 115, respectively). Measurements are on the left, and VOACAP predictions are on the right. The solid lines are (from the top) the upper decile, median and lower decile. Note that on this scale, the experimental system is incapable of observing signals below about $-150 \mathrm{dBr}$. The solid bar at the top of each panel is described in Figure 2.

the GCP direction of about $46^{\circ}$, while the median values of $\Delta A$ during the day (not shown here) were small and tend to decrease with increasing frequency, ranging from $3^{\circ}$ at $4.6 \mathrm{MHz}$ to $1^{\circ}$ at $18.4 \mathrm{MHz}$. At night, the measured azimuth and $\triangle A$ are highly dependent on season and frequency. For the midsummer months (June and July), the nighttime median measured azimuth tends to be close to $\mathrm{GC}$ and the upper-decile values of $\Delta A$ less than $10^{\circ}$ for all frequencies. In the winter months, the behavior depends on the frequency. For intermediate frequencies $(7.0-11.1 \mathrm{MHz})$, the signal arrives with a median azimuth about $30-40^{\circ}$ below the GC azimuth (i.e., to the north), while the upper-decile, owing to the presence of sporadic $E$ layers, lies close to the GC direction. The median and upper-decile values of $\Delta A$ are more than $30^{\circ}$ and $40^{\circ}$, respectively. The off-GCP propagation is associated with the modes with long TOF and usually occurs when the operating frequency is above the median MUF predicted by VOACAP, i.e., when on-GC propagation is not usually supported. For $4.6 \mathrm{MHz}$, much of the propagation is on-GC (median $\triangle A$ of $3^{\circ}$ ), and while there are some instances of off-GC propagation these tend not be as pronounced (upper-decile $\Delta A=19^{\circ}$ ) or as common as for the intermediate frequencies. For the higher frequencies (14.4 MHz and $18.4 \mathrm{MHz}$ - results not shown), propagation at night is, as predicted, rare but when it does occur is generally off-GC by a few tens of degrees or, if on $\mathrm{GC}$, via a sporadic $E$ layer. It is important to note that VOACAP would always predict a fixed value of $46^{\circ}$ (i.e., the GC direction) since it does not account for propagation which takes place away from the GCP.

[17] The median and upper and lower deciles of the signal strength observed experimentally and derived from VOACAP for 11.1 MHz are presented in Figure 5. In calculating the median and deciles for the signal 


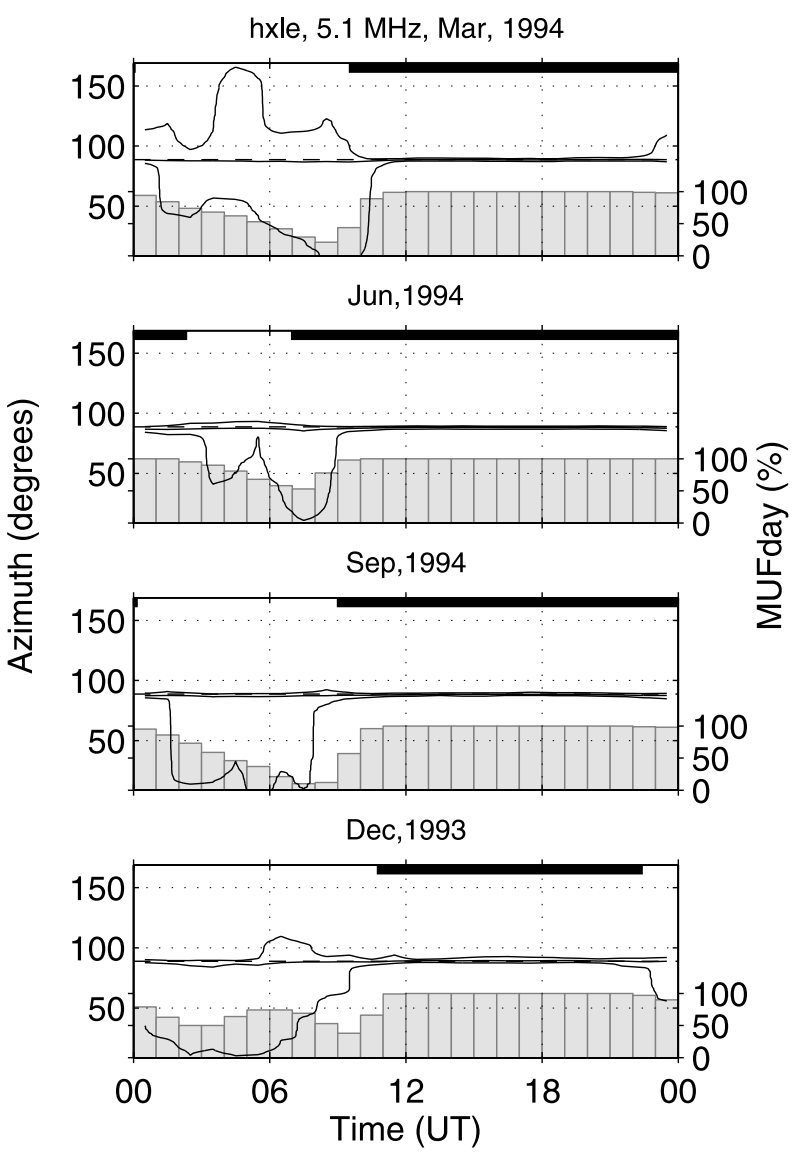

Figure 6. (left axis) Lower decile (bottom line), median (middle line), and upper-decile (top line) of azimuth measured on Halifax-Leitrim path for $5.1 \mathrm{MHz}$ in March, June, and September 1994 and December 1993 (SSN = $34,31,27$, and 38 , respectively). The dashed line represents the great-circle direction. (right axis) Histogram of the probability of the operating frequency being below the MUF predicted by VOACAP. The solid bar at the top of each panel is described in Figure 2.

strength, the instances where the signal was too weak to be detected have been tagged as 'not received'. If the median or deciles have this 'undetected signal' value then they have been omitted from the figure (hence the gaps). In calculating the predicted values, the transmitted power of $80 \mathrm{~W}$ employed in the experiment has been used, although this has been reduced by $2 \mathrm{~dB}$ in order to account for cable losses [Lane, 2001]. Antenna radiation patterns corresponding to ITU-R705 vertical monopoles [ITU-R, 1995] of height of $4 \mathrm{~m}$, with no ground plane have been adopted for both transmitter and receiver. While the chosen antenna represents a reasonable approximation for the receiver site, it is likely to be less accurate for the transmitter. Because of these approxi- mations, it is expected that the absolute measured signal strength may differ from the prediction. However, in order to compare the results, the experimental values have been adjusted so that the median values at dawn in the winter (since there is a good agreement between the observed and predicted propagation mode and minimal $D$ region absorption at that time) are close in value to the predicted ones. The same adjustment (which is frequency dependent) is then used for all hours and months. Examination of Figure 5 reveals that the daytime median values in all seasons are predicted with reasonable accuracy by VOACAP. However, the observed $D$ region absorption is slightly more pronounced than that predicted, although the opposite is the case for lower frequencies (not shown here - although see HalifaxLeitrim results). The predicted lower decile is further from the median than the measured one, particularly before noon in winter and at all times for other seasons. At night, the predictions in summer conform reasonably well to the observations, but this is not the case for other seasons. In winter, the observed signal strength is at times $10 \mathrm{~dB}$ or more greater than that predicted by VOACAP (e.g., 0000-0200 UT for the median and 0200-0600 UT for the upper decile). This arises because of the off-GC propagation at long-TOF that is observed, but not predicted. In the spring and autumn, the predicted signal strength is also somewhat higher than that observed. It is possible that this happens because VOACAP overestimates the MUF on the path since the trough is not explicitly included and therefore predicts an on-GCP reflection where this does not occur.

\subsection{Trough Path Near Sunspot Minimum (Halifax-Leitrim)}

[18] The seasonal variation of median and upper and lower deciles of the azimuthal angle of arrival together with the probability of the MUF exceeding the operating frequency predicted by VOACAP (known as MUFday or mode probability) for $5.1 \mathrm{MHz}$ on the Halifax-Leitrim path is presented in Figure 6. During the day, particularly when MUFday is around $100 \%$, the $5.1 \mathrm{MHz}$ signal is received on-GC. At night, the observations are more likely to be off-GC as MUFday decreases. This behavior is consistent with signal reflection via the walls of the trough becoming the dominant mechanism once the electron density on the great circle is insufficient to support propagation. It is interesting to note that while the deviation from the great circle was predominantly to the north in the Uppsala-Leicester measurements, deviations in either (or sometimes both) direction (e.g., top panel of Figure 6) were found on the Halifax-Leitrim path. Ray-tracing studies [Siddle et al., 2004b] have suggested that the different gradients found in the equatorward wall of the trough at solar minimum and solar maximum may be the cause of this change in behavior. 
Table 2. As Table 1, Except for Halifax-Leitrim Around Corrected Geomagnetic Midnight (0200-0600 UT) ${ }^{\mathrm{a}}$

\begin{tabular}{cccc}
\hline & & \multicolumn{2}{c}{$5.1 \mathrm{MHz}$} \\
\cline { 3 - 4 } Year & Month & 50 & 90 \\
\hline \multirow{2}{*}{1993} & Nov & 2 & 73 \\
& Dec & 5 & 76 \\
& Jan & - & - \\
& Feb & 2 & 58 \\
& Mar & 4 & 70 \\
& Apr & 4 & 73 \\
& May & 3 & 44 \\
& Jun & 3 & 41 \\
& Jul & 2 & 38 \\
& Aug & - & 74 \\
& Sep & 2 & 82 \\
& Oct & 6 &
\end{tabular}

${ }^{\mathrm{a}}$ The results for months with fewer than 5 days of observations or 100 measurements have been omitted.

Furthermore, while the propagation at night in the summer was almost invariably on-GC for UppsalaLeicester, for Halifax-Leitrim, off-GC propagation does occur, albeit less often than in the winter months and with smaller deviations from the GC direction. No observations for the two higher frequencies $(10.9 \mathrm{MHz}$ and $15.9 \mathrm{MHz}$ ) are presented because signal identification at night was problematic, whilst during the day the signal tended to be within a few degrees of the GC direction.

[19] The median and upper-decile values of the absolute deviation in azimuth from the GC direction $(\Delta A)$ for a four-hour interval centered on corrected geomagnetic local midnight are given in Table 2. The observations during the day (1400-1800 UT) are not presented since the propagation was very close to on-GCP with the median and upper-decile values not exceeding $2^{\circ}$ and $5^{\circ}$, respectively. At night, the median is no more than $6^{\circ}$ because the signal is commonly received along the great circle since this frequency is often below the MUF (see Figure 6). The off-GC propagation observed on this path means that the upper-decile values of $\Delta A$ range from over $70^{\circ}$ in the nonsummer months to around $40^{\circ}$ in the summer months. That these values are much higher than those found for the Uppsala-Leicester path (Table 1) for all seasons and frequencies may partly be explained by the differences in the geometries between the two paths (Figure 1). Assuming the reflection comes from a given distance along a line perpendicular to the GC path (e.g., from the northern wall of the trough), then clearly the azimuthal deviation will be greater for the shorter, Halifax-Leitrim, path than for the longer UppsalaLeicester path. In addition, the gradients of the trough walls are different at sunspot maximum and minimum and this may also contribute to the difference in azimuth deviation since the reflection (or scattering) may take place at a different location within the trough wall.

[20] The observed and predicted median and deciles for signal strengths for 5.1 MHz (Figure 7) have been derived following a similar procedure to that described above, for the Uppsala-Leicester path. At night, the measured and predicted signal strengths are in reasonable agreement, although the measured lower decile is further from the median than the predicted one (in contrast to the Uppsala-Leicester results) and the drop in signal strength between 5-10 UT is more severe in the observations than given by VOACAP. This may occur because the effect of the trough on the on-GC MUF is not considered by VOACAP and therefore, it predicts that propagation is more likely than is actually the case. During the day, the effect of the $D$ region absorption expected by VOACAP is more severe than that actually observed.

\subsection{Trans-Auroral Oval Path (Halifax-Alert)}

[21] The observed probability of occurrence (as a percentage of the total number of transmissions) and the median and deciles of the azimuth of arrival have been plotted together with the predicted signal strength and proportion of days in a month for which the operating frequency is below the MUF (MUFday) in Figures 8 and 9 . The effect of smoothed sunspot number (SSN) as it varies from 35 in February 1994, to 23 in 1995, and to 10 in 1996 can be observed in Figure 8. The daytime ( $\sim 10-23$ UT) propagation appears largely unaffected by the change in SSN, with the observed azimuth being largely on-GC, although the signal does arrive from east of the GC around dawn and west of the $\mathrm{GC}$ at sunset, while the probability of occurrence is well correlated with the signal strength predicted by VOACAP. The propagation at night does change with SSN with VOACAP predicting that the signal strength (and MUFday) is higher as SSN increases, while the probability of occurrence also increases (the signal strength threshold for detection is about -170 to $-180 \mathrm{dBW}$ on this scale). In the short interval around 0900-1200 UT in 1994 (and to a lesser extent in 1995), the probability of occurrence does not decrease as expected from the predictions. However, where the signal does propagate at night, it often arrives from off-GC directions, e.g., the upper-decile azimuth is up to $60^{\circ}$ to the west of the GC in 1994, behavior that is not predicted by VOACAP and this may account for this discrepancy.

[22] The effect of changing frequency can be observed by comparing the top panels of Figure 8 with those in Figure 9 and by examination of Table 3, where values of $\Delta A$ are presented. For all three frequencies, the probability of occurrence is reasonable well correlated with the predicted signal strength. However, for $5.1 \mathrm{MHz}$ the 

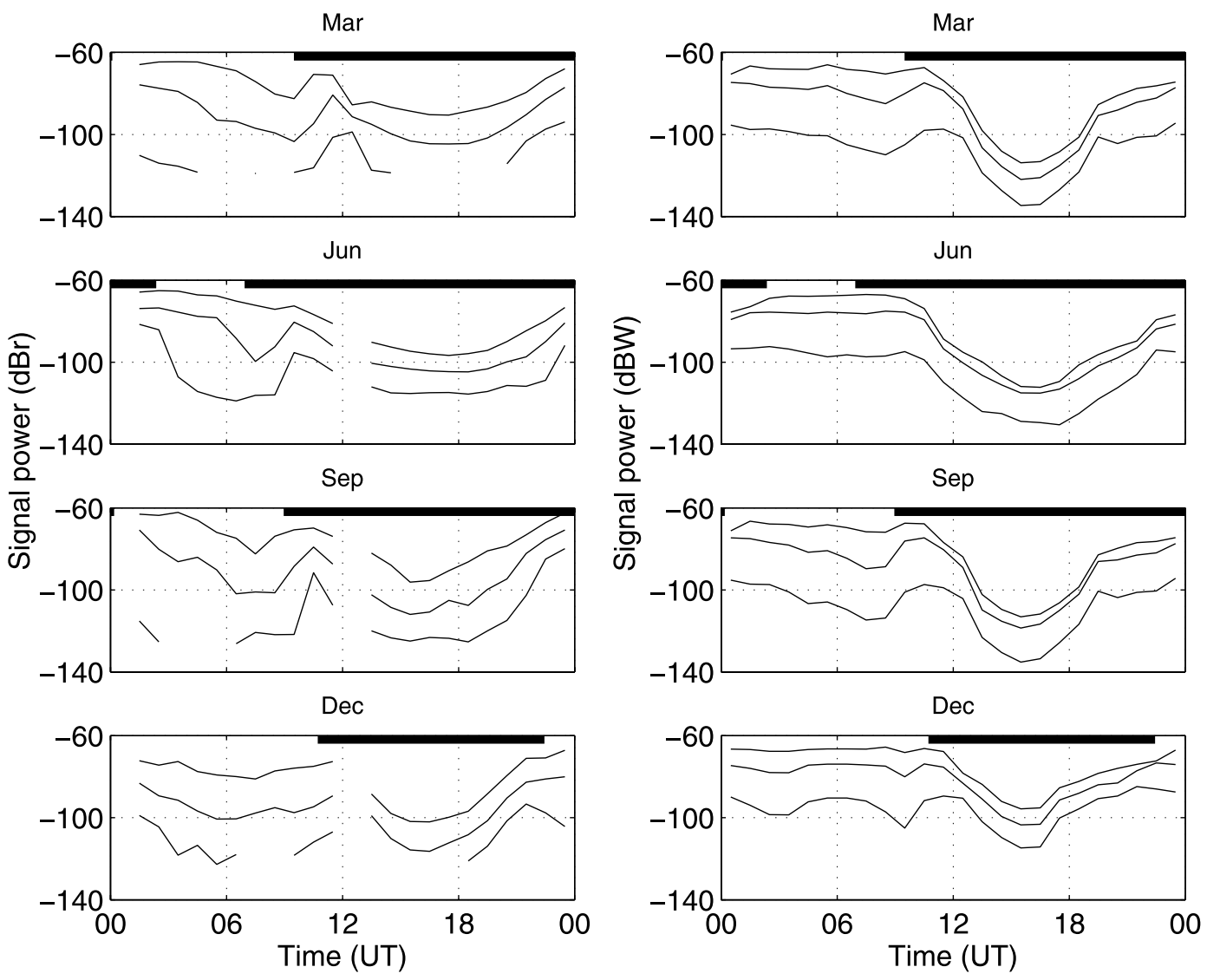

Figure 7. Seasonal variation in signal strength on the Halifax-Leitrim path at $5.1 \mathrm{MHz}$ in March, June, and September 1994 and December 1993 (SSN = 34, 31, 27, and 38, respectively). The observations are in the left-hand panels, and the VOACAP predictions are in the right. The solid bar at the top of each panel is described in Figure 2.

recovery of the signal from the midday $(\sim 1600 \mathrm{UT})$ $D$ region absorption occurs later than predicted, and for $15.9 \mathrm{MHz}$, the propagation that occurs between 0000 and 0300 UT is present in neither the VOACAP signal strength nor MUFday results. The nature of the azimuth of arrival behavior changes with frequency, at $5.1 \mathrm{MHz}$ the signal can arrive from off-GC at any time of the day (except for period within a few hours of $0000 \mathrm{UT}$ ), while for $10.9 \mathrm{MHz}$ off-GC propagation tends to occur at night when MUFday is low and at dawn and dusk, and for 15.9 $\mathrm{MHz}$ the signal also tends arrive from the east of the GC (i.e., azimuths below the GC direction of $181^{\circ}$ ) around sunrise and to the west of the GC at sunset and for a few hours afterwards. The marked difference in the timing of when the signal arrives from off-GC may be explained by differences in mode of propagation as the frequency is changed. VOACAP predicts that the lowest frequency will propagate principally via $2 \mathrm{~F} 2$ and $3 \mathrm{~F} 2$ modes, while for the higher frequencies propagation is normally via a $2 \mathrm{~F} 2$ mode. The first reflection point of the $3 \mathrm{~F} 2$ mode is more likely to be in or close to the auroral zone than that of the 2F2 mode (perhaps leading to an increase in $\Delta A$ ), whilst the second and third reflection points are in the polar cap where the azimuth is more likely to be affected by the large-scale ionospheric features found there. It is noteworthy that the off-GC propagation observed during the day for $5.1 \mathrm{MHz}$ is only found in 1994, when SSN was higher, and not in the subsequent two years (see Table 3 ). The value of $\Delta A$ observed at midnight also tends to vary a little as the SSN decreases (at least for $5.1 \mathrm{MHz}$ and $10.9 \mathrm{MHz}$ ) and some seasonal dependence is also present with the deviations being higher in the winter than the summer.

\subsection{Polar Cap Path (Iqaluit-Alert)}

[23] Observations and VOACAP predictions for $9.3 \mathrm{MHz}$ on the shorter, polar cap, path from Iqaluit to Alert are presented as a function of season in Figure 10. It should 

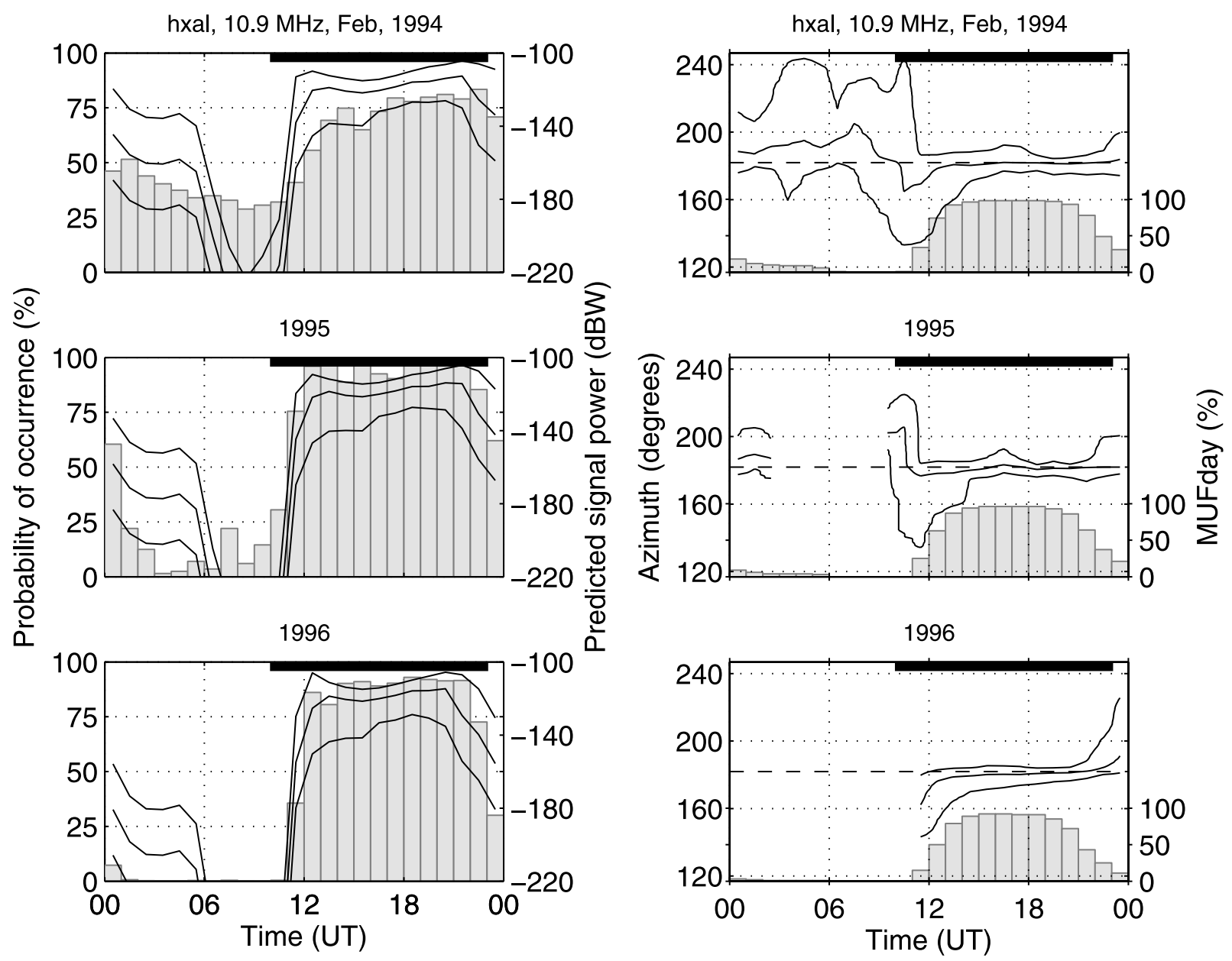

Figure 8. Halifax-Alert, 10.9 MHz. (left) Histogram of probability of occurrence (left axis) and lower decile, median, and upper decile (bottom to top line, respectively) of predicted signal strength (right axis) for February 1994, 1995, and 1996 (SSN = 35, 23, and 10, respectively). (right) Observed lower decile, median, and upper decile of azimuth (left axis) and histogram of the probability predicted by VOACAP of the operating frequency being below the MUF (right axis). The dashed line is the azimuth corresponding to the great circle path. The solid bar at the top of each panel is described in Figure 2.

be noted that while in February, the sunrise and sunset in the $F$ region are at 1000 and 2330 UT, respectively for April and June the $F$ region is sunlit at all times of day (although, of course, the solar zenith angle does vary with time). For all three months, the probability of occurrence is largely constant with time of day although there is a slight reduction in February that corresponds reasonably well with a decrease in the predicted signal strength. The predicted sharp loss in signal strength accompanied by a significant drop in the mode probability between 1500 and 1700 UT in April and at 1000 UT in June is not present in the observations.
Examination of the VOACAP results indicates that for these intervals a weak $2 \mathrm{E}$ mode is predicted that prevents propagation by the usual $1 \mathrm{~F} 1$ or $1 \mathrm{~F} 2$ mode and that the most reliable mode becomes a weak, less probable $2 \mathrm{~F}$ mode. By running VOACAP with a minimum takeoff angle of $0.1^{\circ}$ (rather than $3^{\circ}$ ), a $1 \mathrm{E}$ mode is predicted at an elevation angle of $0.8^{\circ}$ that removes the strong reduction in MUFday and lessens the drop in signal strength. However, since the isotropic transmit antenna we have used in VOACAP is likely to perform significantly better at this elevation than the actual system, it suggests that the VOACAP predictions are inaccurate for 

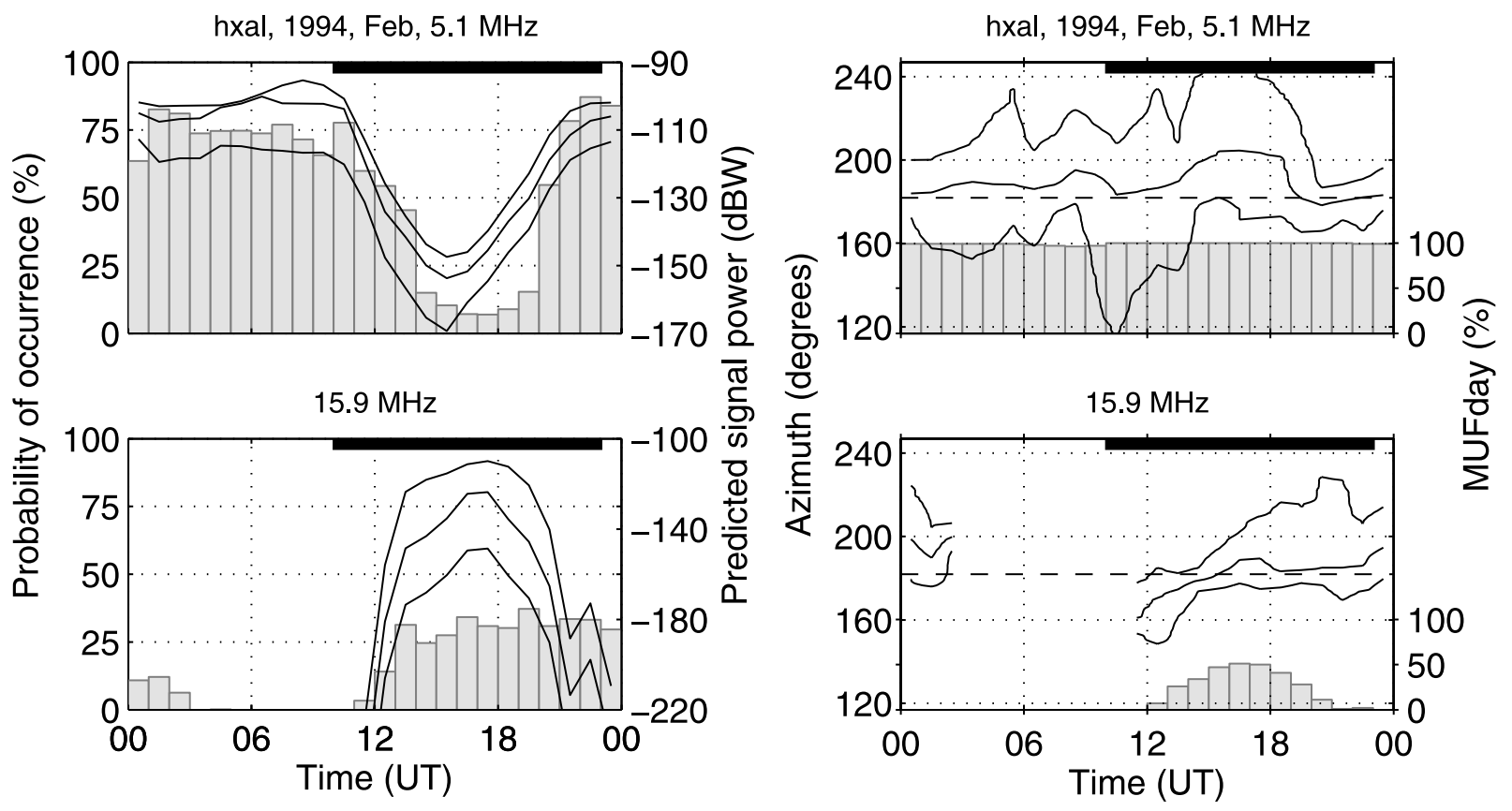

Figure 9. As Figure 8, except for 5.1 and $15.9 \mathrm{MHz}$ in February 1994.

this situation. The probability of off-GC propagation is strongly dependent on the season. During the winter, offGC propagation to both east and west of the great circle is common at night when the predicted probability of propagation is lower, in spring it is mainly deviated to the west, while by summer no significant off-GC is observed. This seasonal variation can also been found in the $\Delta A$ data presented in Table 4. There is some evidence to suggest a weak dependence of the azimuth deviation on sunspot number. For example, for $9.3 \mathrm{MHz}$ in February 1994 the azimuth deviation is about $20^{\circ}$ higher than that found in February 1996. Of course, the data set is limited and the observations do not cover a broad range of SSN values (from 35 to 10 ), so it may be difficult to draw firm conclusions from this without further measurements. Finally, the nighttime azimuth deviations are higher for $9.3 \mathrm{MHz}$ than for $5.8 \mathrm{MHz}$ probably because the on-GC mode probability predicted by VOACAP for the lower frequency is usually close to $100 \%$, whilst for the higher frequency it is around $50 \%$ at night, in winter. Off-GC modes are usually weaker than those propagating on-GC and therefore will only be observed very infrequently when an on-GC mode is present.

\section{Concluding Remarks}

[24] A statistical analysis of observations of the direction of arrival and signal strength have been compared with VOACAP predictions for four paths, two roughly tangential to the midlatitude trough, one trans-auroral, and one entirely located within the polar cap. For propagation on the paths affected by the trough, there is reasonable agreement during the day at all times of year, while at night, particularly in the nonsummer

Table 3. As for Table 2, Except for Halifax-Alert (Noon Indicates 1300-1700 UT, and Midnight 0100-0500 UT) and Only the Upper-Decile Values Are Presented

\begin{tabular}{|c|c|c|c|c|c|c|c|}
\hline & \multicolumn{2}{|c|}{$5.1 \mathrm{MHz}$} & \multicolumn{2}{|c|}{$10.9 \mathrm{MHz}$} & \multicolumn{2}{|c|}{$15.9 \mathrm{MHz}$} \\
\hline & & Noon & Midnight & Noon & Midnight & Noon & Midnight \\
\hline \multirow[t]{5}{*}{1994} & Jan & 23 & 27 & 16 & 48 & 23 & - \\
\hline & Feb & 59 & 42 & 13 & 50 & 20 & 27 \\
\hline & Mar & 92 & 36 & 12 & 53 & 17 & 15 \\
\hline & Apr & - & 12 & 9 & 18 & 5 & 18 \\
\hline & May & - & 19 & 12 & 13 & 7 & 15 \\
\hline \multirow[t]{8}{*}{1995} & Feb & 9 & 25 & 12 & - & 9 & 15 \\
\hline & Mar & 13 & 31 & 12 & 37 & 7 & 14 \\
\hline & Apr & 10 & 24 & 8 & 24 & 10 & 16 \\
\hline & May & 5 & 27 & 10 & 14 & 8 & 19 \\
\hline & Jun & 7 & 24 & 11 & 10 & 10 & 22 \\
\hline & Jul & 12 & 16 & 7 & 10 & 7 & 26 \\
\hline & Aug & - & - & 7 & 23 & 7 & 25 \\
\hline & Sep & - & - & 7 & 23 & 10 & 10 \\
\hline \multirow[t]{2}{*}{1996} & Jan & 15 & 25 & 12 & - & 12 & - \\
\hline & Feb & 6 & 24 & 13 & - & 8 & - \\
\hline
\end{tabular}



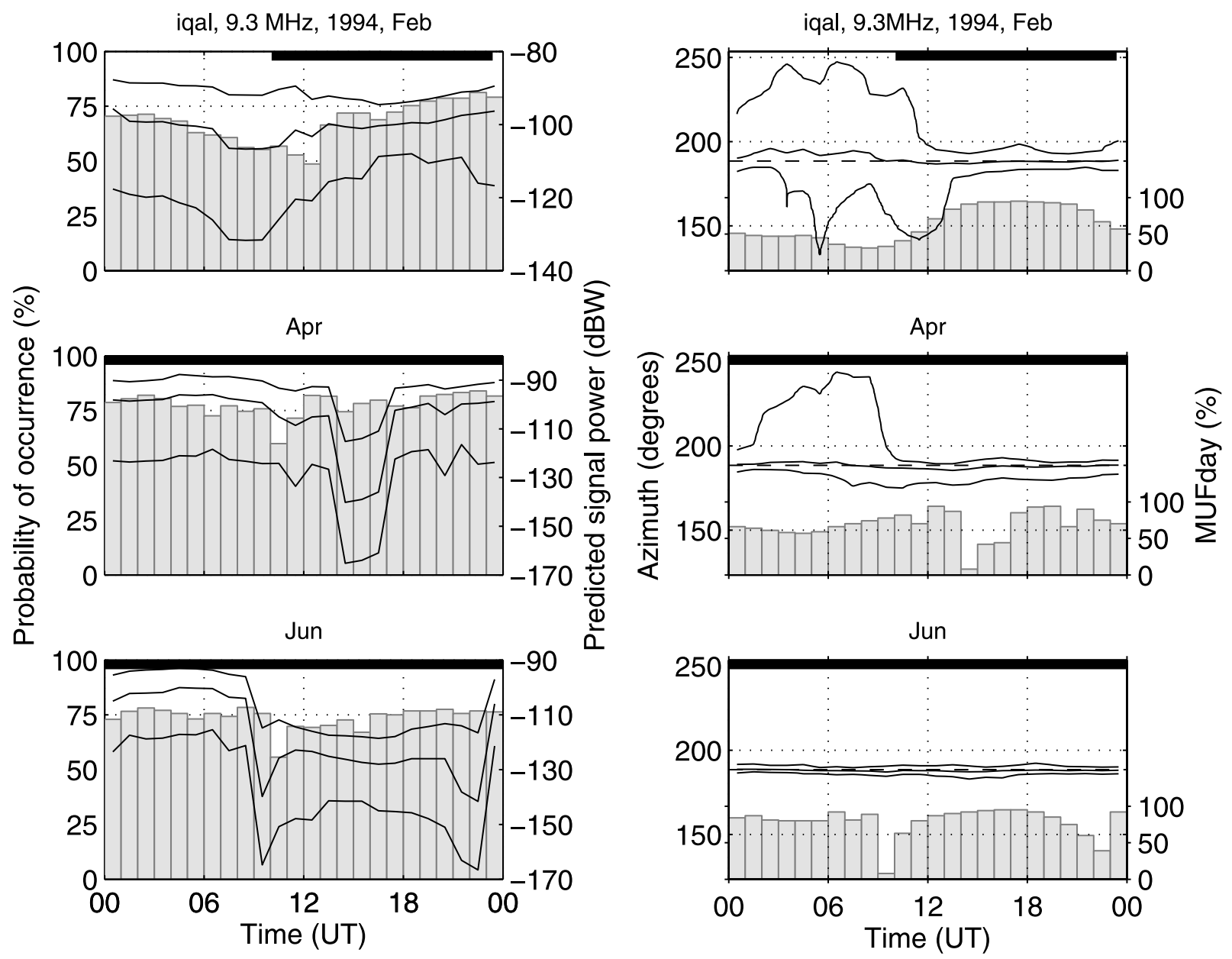

Figure 10. As for Figure 8, except for Iqaluit-Alert at 9.3 MHz in February, April, and June 1994 $(\mathrm{SSN}=35,34$, and 31 , respectively).

months, the agreement in signal strength and mode probability is poor. There is a difference in behavior between the observations made at sunspot maximum and at sunspot minimum. The azimuth deviations at sunspot minimum are larger than those at sunspot maximum, although these may be explained by the differences in path length and geometry. Furthermore, at sunspot minimum, significant upper-decile deviations of up to $40^{\circ}$ are still found in the summer months (albeit smaller than those found in the winter) while propagation from offgreat circle occurs on $20-40 \%$ of nights compared to under $20 \%$ for sunspot maximum.

[25] For the trans-auroral path and the path located entirely within the polar cap, the presence of off great circle propagation was a common feature, the exact behavior of which was different for each path. For the trans-auroral path, upper-decile deviations in the azimuth from the great circle direction of up to $90^{\circ}$ were observed which decrease with decreasing sunspot number and tend to be smaller in the summer than the winter. For most frequencies, the deviations are a nighttime phenomenon; however, frequencies that have a reflection in or close to the auroral oval can also arrive from off great circle during the day. VOACAP can underestimate the signal strength in the presence of off great circle propagation. For the polar cap path, deviations in azimuth from the great circle of up to $70^{\circ}$ have been found around local magnetic midnight, while the values around local magnetic noon do not exceed $20^{\circ}$. The deviations depend on season (summer values are smaller), but less so on sunspot number (although observations are only available for a limited range of, comparatively low, sunspot numbers), and are higher for frequencies closer to the MUF. The observed probability of occurrence is reason- 
Table 4. As for Table 3, Except for Iqaluit-Alert

\begin{tabular}{ccccccc}
\hline & & \multicolumn{2}{c}{$5.8 \mathrm{MHz}$} & & \multicolumn{2}{c}{$9.3 \mathrm{MHz}$} \\
\cline { 3 - 4 } \cline { 6 - 7 } & & Noon & Midnight & & Noon & Midnight \\
\hline \multirow{2}{*}{1994} & Jan & 14 & 19 & & 18 & 71 \\
& Feb & 14 & 37 & & 13 & 58 \\
& Mar & 13 & 17 & & 10 & 44 \\
& Apr & 11 & 18 & & 11 & 38 \\
& May & 7 & 13 & & 7 & 14 \\
& Jun & - & - & & 6 & 4 \\
& Jul & - & - & & - & - \\
& Aug & - & - & & - & - \\
& Sep & - & - & & 6 & 37 \\
& Oct & - & - & & 6 & 46 \\
& Sep & 11 & 18 & & 9 & 41 \\
& Jan & - & - & & 10 & 54 \\
& Feb & 4 & 9 & & 11 & 37 \\
& Mar & 4 & 14 & & 53 \\
& Apr & 4 & 13 & & 4 & 26 \\
& May & 7 & 9 & 9 & 14 \\
\hline
\end{tabular}

ably well correlated with the signal strength predicted by VOACAP. However, occasionally VOACAP predicts a $2 \mathrm{E}$ mode that obscures the $1 \mathrm{~F}$ modes otherwise found which leads to a fall in the expected signal strength that is not observed.

[26] The comparisons presented in this paper illustrate some of the deficiencies in the current HF prediction codes for paths impinging on the northerly ionosphere (and presumably the corresponding regions in the southern hemisphere). It is evident that in order to improve HF propagation predictions over these northerly regions that the off great circle propagation mechanisms need to be taken into account. It is anticipated that the data presented in this paper, together with the results of current experimental investigations, will be used to create and validate a model for predicting off great circle propagation and this will be reported in subsequent papers.

[27] Acknowledgments. The authors are grateful to the EPSRC (grant GN/N16877) for providing financial support to undertake the measurements obtained on the Uppsala-Leicester path, and to the Canadian Department of National Defence for the measurements made within Canada.

\section{References}

Bates, H. F., P. R. Albee, and R. D. Hunsucker (1966), On the relationship of the aurora to non-great-circle HF propagation, J. Geophys. Res., 71, 1413-1420.

Blagoveshchensky, D. V., and T. D. Borisova (2000), Substorm effects of ionosphere and HF propagation, Radio Sci., 35(5), $1165-1171$.

Buchau, J., B. W. Reinisch, E. J. Weber, and J. G. Moore (1983), Structure and dynamics of the winter polar cap $F$ region, Radio Sci., 18(6), 995-1010.
Carlson, H. C., Jr., V. B. Wickwar, E. J. Weber, J. Buchau, J. G. Moore, and W. Whiting (1984), Plasma characteristics of polar cap $F$ layer arcs, Geophys. Res. Lett., 11, 895-898.

Feichter, E., and R. Leitinger (2002), Properties of the main trough of the $F$ region derived from Dynamic Explorer 2 data, Ann. Geophys., 45, 117-124.

Goodman, J. M., and J. W. Ballard (2004), An examination of elevated frequency propagation over a transpolar path, Radio Sci., 39, RS1S29, doi:10.1029/2002RS002850.

Gussenhoven, M. S. (1982), Extremely high latitude auroras, J. Geophys. Res., 87, 2401-2412.

Halcrow, B. W., and J. S. Nisbet (1977), A model of the F2 peak electron densities in the main trough region of the ionosphere, Radio Sci., 12, 815-820.

Holzworth, R. H., and C. I. Meng (1975), Mathematical representation of the auroral oval, Geophys. Res. Lett., 2(9), 377.

Hunsucker, R. D., and J. K. Hargreaves (2003), The HighLatitude Ionosphere and Its Effects on Radio Propagation, pp. 477-482, Cambridge Univ. Press, New York.

International Telecommunication Union-Radiocommunication (ITU-R) (1995), HF transmitting and receiving antennas characteristics and diagrams, Recomm. ITU-R BS.705-1, Geneva.

International Telecommunication Union-Radiocommunication (ITU-R) (2001), HF propagation prediction method, Recomm. ITU-R P.533-7, Geneva.

Lane, G. (2001), Signal-to-noise predictions using VOACAP A user's guide, Rockwell Collins Inc., Cedar Rapids, Iowa.

McNamara, L. F., R. J. Barton, and T. W. Bullett (2006), Analysis of HF signal power observations on two North American circuits, Radio Sci., 41, RS5S38, doi:10.1029/ 2005RS003347.

Rogers, N. C., E. M. Warrington, and T. B. Jones (1997), Large $\mathrm{HF}$ bearing errors for propagation paths tangential to the auroral oval, IEE Proc. Microwaves Antennas Propag., 144, 91-96.

Siddle, D. R., A. J. Stocker, and E. M. Warrington (2004a), The time-of-flight and direction of arrival of HF radio signals received over a path along the midlatitude trough: Observations, Radio Sci., 39, RS4008, doi:10.1029/2004RS003049.

Siddle, D. R., N. Y. Zaalov, A. J. Stocker, and E. M. Warrington (2004b), The time-of-flight and direction of arrival of HF radio signals received over a path along the midlatitude trough: Theoretical considerations, Radio Sci., 39, RS4009, doi:10.1029/2004RS003052.

Stanislawska, I., P. A. Bradley, T. L. Gulyaeva, and H. Rothkaehl (2006), Improved HF propagation and system performance predictions under ionospherically extreme conditions, $A d v$. Space Res., 37, 1069-1074.

Stocker, A. J., E. M. Warrington, and T. B. Jones (2003), A comparison of observed and modeled deviations from the great circle direction for a $4490 \mathrm{~km}$ HF propagation path along the midlatitude ionospheric trough, Radio Sci., 38(3), 1054, doi:10.1029/2002RS002781. 
Sweeney, N. M., F. J. Rhoads, and L. M. DeBlasio (1993), Voice of America coverage analysis program (VOACAP) user's manual, VOA B/ESA/TR-02-93, USIA/SW/CK-93/ 001A, PB93-155174INZ.

Warrington, E. M., and A. J. Stocker (2003), Measurements of the Doppler and multipath spread of HF signals received over a path oriented along the midlatitude trough, Radio Sci., 38(5), 1080, doi:10.1029/2002RS002815.

Warrington, E. M., N. C. Rogers, and T. B. Jones (1997), Large HF bearing errors for propagation paths contained within the polar cap, IEE Proc. Microwaves Antennas Propag., 144(4), 241-249.

Weber, E. J., J. Buchau, J. G. Moore, J. R. Sharber, J. D. Livingston, J. D. Winningham, and B. W. Reinisch (1984), F layer ionization patches in the polar cap, J. Geophys. Res., $89,1683-1694$.
Whale, H. A. (1969), Effects of Ionospheric Scattering on VeryLong-Distance Radio Communication, Plenum, New York.

Zaalov, N. Y., E. M. Warrington, and A. J. Stocker (2003), Simulation of off-great circle HF propagation effects due to the presence of patches and arcs of enhanced electron density within the polar cap ionosphere, Radio Sci., 38(3), 1052, doi:10.1029/2002RS002798.

Zaalov, N. Y., E. M. Warrington, and A. J. Stocker (2005), A ray-tracing model to account for off-great circle HF propagation over northerly paths, Radio Sci., 40, RS4006, doi:10.1029/2004RS003183.

D. R. Siddle, A. J. Stocker, and E. M. Warrington, Department of Engineering, University of Leicester, Leicester LE1 7RH, U.K. (emw@le.ac.uk) 